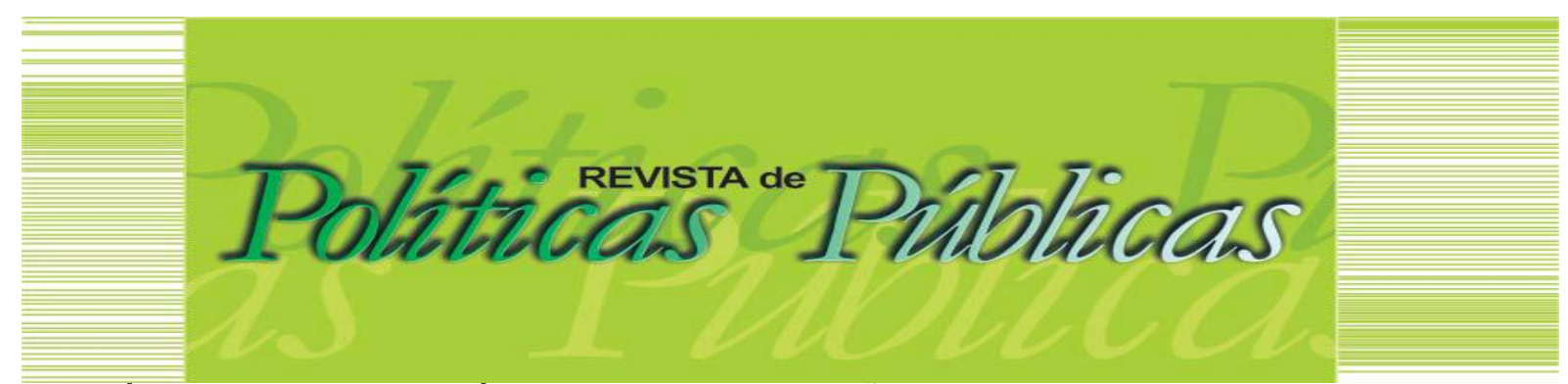

\title{
TENDÊNCIAS CONTEMPORÂNEAS DA PARTICIPAÇÃO POPULAR: experiências dos Conselhos Municipais de Saúde do Espírito Santo ${ }^{1}$
}

Ana Targina Rodrigues Ferraz ${ }^{2}$

\begin{abstract}
Resumo
Este artigo sintetiza os principais resultados de pesquisa desenvolvida acerca das tendências contemporâneas da participação popular a partir da experiência de participação no âmbito dos conselhos municipais de saúde do estado do Espírito Santo. O principal objetivo do estudo é demonstrar como as novas modalidades de organização, mobilização e comunicação dos movimentos sociais (coletivos, redes e fóruns) afetaram os processos de participação popular no âmbito da política de saúde, especialmente as estratégias de informação e comunicação, a estrutura e dinâmica de funcionamento dos conselhos. É um estudo de caso cuja coleta de dados foi realizada por meio da análise de documentos públicos e sites, acompanhamento das redes sociais de movimentos e conselhos, observação das reuniões de movimentos e conselhos e entrevistas. O principal resultado da pesquisa é a constatação da existência de um hiato entre os mecanismos de participação construídos como forma de viabilizar a democracia participativa e as demandas por participação direta de coletivos, redes e fóruns.
\end{abstract}

Palavras chave: Participação popular. Movimentos sociais. Conselhos de saúde.

\section{CONTEMPORARY TRENDS IN PUBLIC PARTICIPATION: the experiences of municipal health councils in Espírito} Santo

\section{Abstract}

This article synthesises the main results of research around contemporary trends in public participation drawn from the experiences of Municipal Health Councils in Espírito Santo. The main objective of the study was to demonstrate how new modes of organization, mobilization and communication of social movements (collectives, networks and forums) affect the processes of public participation in the ambit of health policy. This is a case study whose data the collection of data was carried out through the analysis of public documents and websites, following the social networks of social movements and councils, observation on the meetings of social movements and councils, and interviews. The main result of the research is the finding of a gap between the participation mechanisms built as a way to make participatory democracy viable and the demands for direct participation of collectives, networks and forums.

Keywords: Public participation. Social movements. Health Councils

Artigo recebido em: 12/01/2020 Aprovado em: 13/10/2020 DOl: http://dx.doi.org/10.18764/2178-2865.v24n2p721-736.

\footnotetext{
1 Pesquisa registrada sob o número 7001/2016 na Pró-Reitoria de Pesquisa e Pós-Graduação da UFES e no comitê de ética em pesquisa da universidade sob o número 65094817.4.0000.5542, aprovada em junho de 2017 (parecer 2.104.465). 2 Assistente Social. Doutora em Ciências Sociais pela UNICAMP. Professora Associada do Departamento de Serviço Social e do PPPGS da Universidade Federal do Espírito Santo - UFES E-mail: anatargina@uol.com.
} 


\section{INTRODUÇÃO}

A democracia participativa e a consequente institucionalização de mecanismos de participação popular nos anos 1990 e 2000, no Brasil, foram objeto de inúmeros estudos em diversas áreas do conhecimento no interior das universidades brasileiras ${ }^{1}$ e no exterior. Um olhar entusiasmado e pouco realista marcou os primeiros trabalhos sobre as experiências de Orçamento Participativo (OP) e Conselhos Gestores de Políticas Públicas, fazendo com que as expectativas de democratização das relações políticas entre Estado e Sociedade Civil, entre agentes públicos e o setor privado tivessem forte influência sobre as primeiras análises, dando às mesmas um caráter quase prescritivo.

A construção da arquitetura institucional que possibilitaria a incorporação de organizações da sociedade civil (associações, organizações não governamentais/ONGs, entidades de classe e movimentos sociais) ao processo decisório no âmbito do Estado foi tratada como um importante componente do processo de democratização. Tão importante que alguns autores afirmaram que 0 sucesso dos experimentos de democracia participativa (OP, Conselhos Gestores de Políticas Públicas, Conferências, mas especialmente do $\mathrm{OP}$ ) dependeria, basicamente, da articulação de três variáveis: a) a tradição associativa existente no município; b) a vontade política dos gestores para a efetiva partilha de poder; c) o desenho institucional assumido pelas experiências de participação (AVRITZER, 2003, 2009). Desconsiderando, portanto, os limites das democracias liberais e seu caráter basicamente procedimental e autorizativo, em que as escolhas populares são processos de autorização para partidos e coalizões partidárias governarem o Estado (SHUMPETER, 1984); as relações assimétricas entre os representantes dos interesses das diferentes classes sociais quanto aos recursos de poder disponíveis para divulgação de suas demandas e para o exercício de pressões sobre os órgãos do Estado (Executivo, legislativo, judiciário) e os limites orçamentários e institucionais.

A construção legal e a implementação dos mecanismos de participação popular após a constituição de 1988, especialmente os mecanismos de controle da gestão de políticas públicas (conselhos e conferências), exigiu enorme esforço político de organizações da sociedade civil. Inúmeros encontros, reuniões e acordos foram necessários entre essas organizações e os legislativos municipais, estaduais e o congresso nacional para a produção das leis orgânicas de cada política e do modelo de funcionamento de seus mecanismos de elaboração e fiscalização.

A construção dessa democracia de novo tipo, com instâncias decisórias capazes de incorporar os novos sujeitos sociais coletivos surgidos nos anos 1970 e 1980, estabeleceu-se em um contexto de questionamento neoliberal dos Estados Sociais e de pouco avanço na participação de trabalhadores, mulheres, negros e imigrantes no mundo inteiro. Ou seja, o caráter elitista das democracias representativas que privilegia homens brancos, escolarizados e de alta renda, não se 
alterou substancialmente. Neste contexto, as organizações da sociedade civil no Brasil se envolveram na construção dos mecanismos de participação popular.

Além desse contexto, os traços mais marcantes das democracias liberais representativas, o distanciamento entre representantes e representados após as eleições, a autonomia decisória quase absoluta dos representantes em relação a seus representados e a apatia política passaram a também caracterizar o funcionamento dos conselhos gestores de políticas públicas (FERRAZ, 2005). O caráter representativo desses espaços impôs limites e constrangimentos à ampliação da participação democrática na medida em que requisitou dos representantes das organizações da sociedade civil 0 exercício das tarefas necessárias à representação: a frequência regular às reuniões, a participação em comissões, a leitura de documentos e a fiscalização dos órgãos e atividades que compõe a política pública, reduzindo as condições para que suas lideranças e participantes mantivessem as atividades de coordenação e de mobilização dos movimentos sociais, de articulação e discussão política, afastando-os cada vez mais da sociedade civil e aproximando-os do Estado (TATAGIBA, 2010). Também a persistência de uma cultura política autoritária e de práticas políticas em que predominam a troca de favores, o uso privado da coisa pública, a cooptação e o clientelismo, dificulta o exercício da participação e do controle social pelos conselhos (BRAVO; MENEZES, 2012).

As expectativas de que a participação popular pudesse ampliar a influência da maioria dos cidadãos brasileiros sobre as decisões do Estado, revertendo seu caráter privatista e autoritário e distribuindo de maneira mais equitativa os seus recursos, não se concretizaram.

A chegada do Partido dos Trabalhadores (PT) à presidência da república, em 2002, deu contornos particulares ao processo de esvaziamento das experiências de participação popular. O PT foi o grande propagador do chamado projeto democrático-participativo e das experiências de participação popular, especialmente o OP. As administrações municipais petistas nos anos 1980 e 1990 estabeleceram uma metodologia própria para a discussão do orçamento municipal (o montante de recursos destinados a investimentos) e o transformaram em uma das principais propostas do projeto democrático participativo. O OP impulsionaria o envolvimento popular na definição do uso a ser dado a uma parcela (os recursos destinados a investimentos) do orçamento do Estado, de modo a promover uma inversão de prioridades em favor dos trabalhadores pobres. Uma vez na presidência da república, a participação popular na discussão do orçamento da união não foi viabilizada. Em contrapartida, além das conferências e conselhos instituídos em legislação nacional, inúmeros outros conselhos e conferências das mais diferentes temáticas² (mulheres, população negra e população LGBT, das cidades, da juventude, segurança alimentar, esportes, medicamentos e assistência farmacêutica, etc.) tiveram lugar na gestão federal em um aparente esforço de democratização do Estado (BEZERRA, 2016). Tais espaços, naquele momento, podem ser caracterizados como mecanismos de 
apassivamento social, em que a conciliação, o consenso e a cooptação pautam as relações entre governo e organizações da sociedade civil.

Muitas lideranças e participantes de movimentos sociais próximos ao Partido dos Trabalhadores passaram a ocupar cargos de confiança na administração federal, nos conselhos gestores de políticas públicas e nos conselhos dos fundos de recursos para políticas públicas e programas. Se por um lado essa inserção possibilitou a incorporação de algumas demandas importantes dos trabalhadores e da população pauperizada (como o aumento real do salário mínimo, o aumento dos empregos formais, a ampliação do acesso ao crédito e ao ensino superior), por outro esvaziou muitos movimentos sociais por envolver suas principais lideranças e criar canais de comunicação e negociação com o governo federal que dispensavam a articulação e a mobilização dos movimentos.

No governo federal o PT aprofundou uma tendência observada desde meados dos anos 1990 a privilegiar os processos eleitorais, a ocupação de órgãos do Estado, a conciliação e a negociação entre as classes. Neste sentido, a dinâmica representativa de funcionamento dos conselhos e das conferências faz com que estes mecanismos sejam capazes de colocar no mesmo espaço, os representantes de diferentes forças políticas debatendo, na maioria das situações, questões referentes à implementação e execução da política (aprovação de contratos, convênios, prestação de contas, autorização para modificações no orçamento, fiscalização de ações), tornando-os quase irrelevantes no circuito decisório envolvendo as prioridades e o desenho das políticas públicas (TATAGIBA, 2010). Ao mesmo tempo, os conselhos proporcionam aos representantes da sociedade civil maior conhecimento acerca do funcionamento da máquina do Estado e da legislação que regula a política. Para os gestores, os conselhos podem constituir espaços nos quais podem divulgar e defender seus projetos e programas e estabelecer uma relação de confiança com lideranças e participantes de movimentos sociais.

\footnotetext{
Os governos têm resistido - de forma mais ou menos acentuada dependendo da natureza do governo e do seu projeto político - às novas formas de fiscalização, controle e participação da sociedade civil no processo de produção das políticas públicas. Os estudos mostram que os governos têm mobilizado estratégias as mais diversas para anular o potencial deliberativo dos conselhos, reduzindo-os, quando muito, a espaços destinados a aumentar a "escuta" e ampliar a audiência em torno dos temas que compõem a agenda pública. (TATAGIBA, 2010, p.37)
}

Em virtude de tais características e de um funcionamento muito similar ao do parlamento, os conselhos parecem não desempenhar qualquer papel no processo de constituição e mobilização das mais recentes experiências de organização dos movimentos sociais (coletivos, redes e fóruns). Sua existência não impulsionou a constituição desses movimentos; e ocupar o espaço político dos conselhos, influir sobre o desenho e as prioridades das políticas públicas, parece não estar entre suas 
prioridades. Alguns dos mais recentes movimentos sociais conhecem a sua existência, mas também conhecem os seus limites na disputa pelos rumos das políticas públicas. Sabem que as decisões de efetivo impacto sobre o desenho da política (as prioridades, o financiamento e a prestação de serviços) estão concentradas nos órgãos do executivo e do legislativo.

A institucionalização de processos participativos desencorajou os cidadãos a usar políticas de confronto fora dos canais oficiais de participação. Se os cidadãos escolhem usar a contestação política "nas ruas", há um aumento do risco dos governantes não trabalharem com estes cidadãos dentro das instituições participativas. (WAMPLER, 2014, p. 218-219, tradução nossa)

Nesse sentido, os conselhos se transformaram em mecanismos de contenção política de confrontos e em um cenário no qual se expandem novas modalidades de organização de movimentos sociais; consideramos pertinente investigar o fenômeno a partir das seguintes perguntas: Os conselhos gestores da política de saúde e as conferências têm sido capazes de absorver as demandas por maior participação das novas modalidades de organização dos movimentos sociais? De que forma os conselhos gestores da política de saúde têm usado as novas tecnologias de informação e comunicação e as mídias sociais para aprofundar sua capacidade de comunicação com os movimentos sociais e usuários do SUS? Os conselhos têm usado as novas tecnologias de informação e comunicação e as mídias sociais para ampliar o monitoramento e o controle social dos usuários sobre a política de saúde? Como os conselhos têm possibilitado maior transparência às decisões e ações desenvolvidas no âmbito da política de saúde? Como os conselhos têm ampliado a capacidade de participação e de fiscalização dos conselheiros de saúde?

Algumas respostas se esboçaram na pesquisa e trataremos neste artigo os aspectos comuns do desenvolvimento das experiências de participação dos conselhos municipais de saúde de Cariacica, Serra, Vila Velha e Vitória no Espírito Santo³.

\section{COMPOSIÇÃO E ORGANIZAÇÃO DOS CONSELHOS}

A composição e organização dos conselhos municipais de saúde devem obedecer às leis que regulamentam a política (as leis $n^{0} 8.080$ de 19 de setembro de 1990, $n^{0} 8.142$ de 28 de dezembro de 1990 e Lei Complementar n 141 de 13 de janeiro de 2012), decretos (5.839 de 11 de julho de 2006 e 7.508 de 28 de junho de 2011), e a resolução 453 de 10 de maio de 2012 do Conselho Nacional de Saúde. Esta resolução estabelece novas diretrizes para a instituição, reformulação, reestruturação e funcionamento dos conselhos de saúde, permitindo que as organizações representadas nos conselhos definam o tempo de mandato de seus representantes (regras anteriores limitavam a recondução dos conselheiros a apenas mais um mandato consecutivo, agora a renovação dos conselheiros é apenas 
recomendada). Também a renovação das entidades representativas dos usuários, trabalhadores e prestadores de serviços nos conselhos não precisa ser total (no mínimo, 30\% das entidades). A resolução também ampliou os tipos de organização e movimentos sociais que podem representar os diferentes segmentos nos conselhos, incluindo associações e movimentos sociais formais ou não, associações de moradores, entidades ambientalistas, organizações religiosas e científicas, entidades patronais. Tais mudanças, produzidas a partir de sugestões dos conselhos municipais e estaduais de saúde de todo o país, são indicativas das dificuldades que os conselhos têm encontrado para renovar as organizações e os representantes dessas organizações participantes desse espaço. As novas diretrizes possibilitam que uma mesma organização ou movimento social e um mesmo conselheiro exerçam a representação por mais de dois mandatos consecutivos no conselho. Além disso, a ampliação dos tipos de organização e movimentos sociais que podem representar os três segmentos no conselho, também constitui um esforço para que outros sujeitos coletivos possam ocupar este espaço.

Dentre os conselhos estudados neste trabalho, os conselhos municipais de saúde da Serra e de Vitória, têm, entre os representantes dos usuários, movimentos que representam algumas das novas modalidades de organização dos movimentos sociais no país. Na Serra, o Fórum Municipal LGBTI da Serra, conquistou uma cadeira entre os representantes dos usuários na última eleição dos conselheiros (em 2018) e em Vitória, a RNP+4(Rede Nacional de Pessoas Vivendo com HIVIAIDS) representa os usuários do SUS há duas gestões. Nos demais municípios, as organizações representativas dos usuários podem ser caracterizadas como organizações ou movimentos sociais tradicionais. São representantes das Associações e Federações de Associações de Moradores, Associações de Pessoas com Patologias, Associações de Pessoas com Deficiência e Pastorais da Igreja Católica. Embora estas organizações também façam parte dos conselhos municipais de saúde da Serra e de Vitória, a inclusão do Fórum LGBTI do Município da Serra e da RNP+ constituem uma novidade.

\subsection{Assuntos pautados nas reuniões}

Para verificar de que maneira os conselhos têm incorporado as demandas por maior participação, bem como têm incorporado temas e questões postas por diferentes movimentos sociais e organizações da sociedade civil, analisamos as atas das reuniões dos conselhos estudados, as convocatórias das reuniões, as resoluções tomadas e publicadas, bem como observamos algumas reuniões de cada um dos conselhos ${ }^{5}$. Nas reuniões dos conselhos acompanhadas neste trabalho, as mesas diretoras (com composição paritária dos segmentos que fazem parte dos conselhos) definem as 
pautas de discussões e estas giram, invariavelmente, em torno dos seguintes temas: apresentação das ações a serem desenvolvidas dentro dos programas e projetos de saúde das secretarias municipais de saúde ou dos convênios, apresentação de reformulações nas ações desenvolvidas dentro dos programas e projetos de saúde, apresentação de explicações para problemas no desenvolvimento dos serviços da política de saúde (quando requisitadas pelos conselheiros), aprovação de contratos e convênios com estado e união e com instituições privadas (filantrópicas ou lucrativas), discussão da organização interna dos conselhos como a estruturação e funcionamento das comissões de trabalho. As reuniões são, nesse sentido, muito mais momentos para o repasse de informações pelos gestores e para referendar suas ações e menos momentos para a reflexão coletiva, construção de propostas e tomada de decisões sobre temas e questões importantes dentro da política. As pautas das reuniões expressam a redução do papel do conselho ao mero acompanhamento das rotinas de programas e projetos da política de saúde. Não se trata, sequer, de monitoramento, pois o monitoramento exige 0 estabelecimento de parâmetros de funcionamento e de qualidade, a verificação do cumprimento desses parâmetros pelo órgão gestor e a correção de rumos. Acompanhar, no caso dos conselhos estudados, é, na maioria das situações, apenas manter-se informado.

Observamos que em um dos conselhos estudados, em duas reuniões, a precarização da prestação dos serviços (recursos humanos insuficientes, redução do estoque de medicamentos de distribuição gratuita, ausência de insumos básicos) nas unidades de saúde do município e a transferência da gestão de um dos serviços para uma Organização Social foi objeto de discussão, sem, entretanto, que o conselho ou os conselheiros mobilizassem outras organizações da sociedade civil para participação no debate.

\subsection{Estrutura física e funcionamento}

Todos os conselhos estudados têm um espaço adequado para realização das reuniões, espaço próprio para o funcionamento do conselho, secretaria executiva e alguns equipamentos para realização de suas atividades (computadores com acesso à internet, telefone, local para reuniões e armazenamento de documentos). Entretanto, o trabalho de fiscalização dos serviços de saúde não tem sido adequadamente realizado porque, em função do congelamento do orçamento público em todos os níveis da federação, os municípios têm dificuldade para disponibilizar veículos ou passagens para a realização dessa atividade.

Os conselhos estudados funcionam com comissões de trabalho. As mais comuns e, em caráter permanente, são as comissões para acompanhar o orçamento e as finanças da secretaria de saúde, comissões de monitoramento das unidades e serviços de saúde, para o acompanhamento de 
programas e projetos e comissões de capacitação ou educação permanente. Com diferentes nomes em todos os municípios estudados apareceram comissões para acompanhar a política e a implantação de conselhos locais de saúde. Tem sido comum em todos os municípios a dificuldade no funcionamento das comissões. Elas precisam ser compostas por membros de todos os segmentos representados nos conselhos, o que dificulta a criação de uma agenda de reuniões e trabalho que seja capaz de contemplar as condições para a participação de todos os envolvidos. Participar das comissões também representa uma carga extra de trabalho dentro do conselho. Foi possível notar que muitos conselheiros desconhecem as tarefas que cabem aos conselhos, o seu funcionamento e as implicações políticas e práticas da atuação como conselheiro. Tal desconhecimento contribui para que os conselhos funcionem, fortemente, como espaço para a mera exposição e justificação das ações do executivo municipal.

Uma outra consequência desse desconhecimento é o descompromisso de conselheiros (especialmente entre os representantes dos trabalhadores da saúde) com o conselho. Não comparecer às reuniões ou não participar das comissões são práticas comuns. O que por vezes dificulta o próprio funcionamento do conselho, pois nas reuniões, por vezes, é necessário explicar por que tal assunto está na pauta, por que será discutido de um jeito e não de outro. Não podemos deixar de considerar que esses representantes, por vezes, são sindicalistas, membros de conselhos profissionais, ou participantes de outros conselhos e organizações, o que dificulta centrar-se em seu papel como conselheiro de saúde. Ao mesmo tempo, essa desconexão entre conselheiros e o próprio conselho contribui para a desconexão entre conselho e sociedade.

No município da Serra o não funcionamento da comissão responsável pela avaliação do Plano Municipal de Saúde por quase 05 meses, fez com que, ao se reunir para avaliar o plano, a comissão não tivesse mais do que 02 semanas para avaliar e apresentar o seu parecer no plenário do conselho. A discussão do plano foi feita em apenas 02 reuniões e este aprovado sem grandes questionamentos, embora apresentasse problemas no diagnóstico da situação da saúde dos moradores e na proposição das metas. ${ }^{6}$

\subsection{Estratégias de comunicação e articulação}

Devemos destacar que a visibilidade dos conselhos municipais de saúde para o conjunto da sociedade é bastante baixa. As informações sobre cada um dos conselhos estudados neste trabalho nos portais das respectivas prefeituras não são encontradas facilmente, mesmo quando buscamos o nome do conselho municipal de saúde de cada município no "Google". Em Cariacica, Serra e Vila Velha, o primeiro passo após entrar no portal da prefeitura é entrar na página da secretaria 
municipal de saúde e dentro da página da secretaria de saúde procurar o conselho municipal. As informações disponíveis sobre os conselhos municipais de saúde são mínimas. Em Cariacica é possível encontrar endereço, telefone e e-mail; na Serra, cronograma das reuniões (onde estão o endereço e o telefone do conselho), composição do conselho (documento inacessível), lei de criação, regimento interno, resoluções e editais; em Vila Velha estão disponíveis (o conselho está no link "setores" da secretaria de saúde) lei de criação do conselho, dia e horário das reuniões, endereço, algumas atas e resoluções, não há regularidade, nem atualização das informações. Em Vitória, após entrar no portal da prefeitura, é preciso entrar no link "Prefeitura" e procurar "Conselhos Municipais". No link do conselho municipal de saúde estão disponiveis lei de criação do conselho, regimento interno, endereço e telefone e no link "Documentos do Conselho" é possível encontrar atas, resoluções, convocações para as reuniões do conselho, calendário de reuniões, composição atualizada. As informações relativas às datas e horários das reuniões não estão facilmente disponíveis, bem como as pautas e atas das reuniões realizadas. Os conselheiros também não estabeleceram formas alternativas de comunicação com os usuários da política de saúde e com a sociedade de um modo geral. 0 whatsapp e o facebook têm sido usados para comunicação entre os próprios conselheiros. Ainda que estas ferramentas possibilitem atingir mais pessoas, o circuito de comunicação continua bastante fechado. As mensagens circulam entre os conselheiros e membros de suas organizações. Mesmo ferramentas simples de comunicação como cartazes nas unidades de saúde informando dia e horário das reuniões do conselho, ou formas de entrar em contato com o conselho e os conselheiros não são utilizadas.

Nesse sentido, o fato de a resolução 453 de 10 de maio de 2012 ter ampliado o leque de organizações e associações que podem representar os diferentes segmentos nos conselhos de saúde, parece ser uma resposta a essa necessidade de ter dentro dos conselhos organizações que possam representar a diversidade de sujeitos coletivos que fazem parte da sociedade brasileira contemporaneamente. Entretanto, essa resposta esbarra no pouco esforço despendido pelos conselhos municipais para divulgar suas ações e para ampliar os participantes nos processos eleitorais para escolha dos representantes. Cobranças para melhorar as estratégias de comunicação dos conselhos municipais estudados foram feitas pelos conselheiros representantes dos usuários de forma mais contundente em Cariacica, em que os conselheiros chegaram a solicitar ao gestor um plano de comunicação para o conselho e decidiram criar um perfil do conselho no facebook. 0 mesmo não foi observado nos conselhos municipais dos demais municípios.

Em Cariacica, Serra, Vila Velha e Vitória, além dos movimentos sociais tradicionais (associações de moradores, movimento sindical, associações de portadores de patologias, pessoas deficientes, movimentos de mulheres, população negra e população LGBT) existem coletivos jovens de 
Hip-Hop, de educação, de jovens feministas e LGBT, que se preocupam com a situação dos jovens negros das periferias do Espírito Santo, das mulheres, da população LGBT. O rap, a dança de rua, o grafite, as batalhas, as rodas de conversa, os cursinhos Pré-Enem, os blocos de rua, os sarais de poesia, as páginas no facebook e no instagram denunciam a miséria, a violência, o preconceito, a discriminação, mas ao mesmo tempo buscam fortalecer-se como comunidade de iguais e exaltam a cultura, a produção cultural, a capacidade de resistir e enfrentar as adversidades. Nenhum desses grupos tem qualquer relação com os conselhos municipais de saúde. Também os conselhos não têm qualquer estratégia de aproximação ou de escuta das demandas desses grupos, como se fizessem parte de mundos completamente distintos.

A ação dos conselhos municipais de saúde se circunscreve ao âmbito da política e da democracia em sentido restrito, com leis, normas, resoluções e procedimentos que enquadram a apresentação das demandas dos usuários da política e estabelecem ritos ${ }^{7}$ para a discussão dos mais prementes problemas de saúde da população. Sua estrutura, seu modelo e ritmo de funcionamento são, em quase tudo, similares ao parlamento. Comporta pouco espaço para a participação direta, para a discussão em profundidade das questões substantivas da política de saúde, envolvendo todos os interessados no tema. Não há a proposição, por exemplo, de assembleias ou plenárias populares para discutir determinados temas ou programas, ou mesmo a criação de grupos de trabalho com a participação de representantes de outras organizações da sociedade civil também para discussão e apresentação de propostas para os problemas da política. Ao mesmo tempo, essa dinâmica de funcionamento dos conselhos tem anulado a capacidade de pressão dos movimentos sociais representados no espaço na medida em que seus quadros fazem parte de sua composição e pouco questionam os seus ritos.

Nesse sentido, a organização dos Fóruns municipais e estaduais em defesa da saúde, da Frente Nacional Contra a Privatização da Saúde, dos Núcleos Estaduais da Luta Antimanicomial, dos Fóruns Estaduais e Municipais da População LGBT, com sua organização pouco formal, fluida, reunindo simultaneamente usuários e trabalhadores do SUS, tem denunciado as sucessivas medidas de privatização da política ${ }^{8}$ e de regressão de avanços antes conquistados nas políticas de saúde mental e saúde da população LGBT. A defesa dos princípios da Reforma Sanitária Brasileira ${ }^{9}$ é a mais importante bandeira. Tais movimentos são núcleos de resistência ao processo de precarização e desmonte do SUS e tem procurando ampliar os defensores dos avanços representados pela Reforma Sanitária entre as trabalhadoras e trabalhadores do sistema, entre usuários e conselheiros por meio de cursos e seminários de formação política, encontros de profissionais e usuários nos espaços dos serviços, plenárias populares, manifestações de rua, produção de documentos e ações jurídicas. 
Esses movimentos exercem sobre o executivo e os conselhos uma modalidade de pressão diferente da exercida pelos movimentos sociais que participam dos conselhos. Estes últimos estão quase sempre muito comprometidos com as regras de funcionamento do espaço. Um comprometimento que não atinge coletivos, redes e fóruns que, por não ocuparem este espaço institucionalizado, podem tanto fazer críticas mais contundentes aos gestores e à política quanto mobilizar diferentes sujeitos coletivos e indivíduos na defesa de suas críticas e propostas ${ }^{10}$.

\section{CONCLUSÕES}

A realização desta pesquisa foi motivada pela efervescente atmosfera política vivida no Brasil após as massivas manifestações de rua em 2013 e das ocupações de escolas e universidades por secundaristas e universitários em 2015 e 2016. Bandeiras à esquerda e à direita do espectro político eram defendidas por coletivos, redes e fóruns, organizados de forma menos hierárquica, mais fluida, descentralizada e democrática, fazendo uso intensivo das novas tecnologias de informação e comunicação. A crítica aos acordos, à conciliação e às negociações típicas das relações entre partidos, governos e organizações tradicionais da sociedade civil no período pós-constituição de 1988, também constitui um elemento comum, levando-nos a questionar de que maneira essas novas modalidades de organização dos movimentos sociais poderiam influenciar os mecanismos de participação popular (conselhos e conferências) para gestão de políticas públicas construídos nos anos 1990. Tais mecanismos foram criados em um contexto similar no final dos anos 1980 e início de 1990, como uma estratégia de renovação das instituições democráticas liberais, de reconhecimento da legitimidade política dos movimentos sociais e de sua capacidade para intervenção nos processos decisórios. A criação de novas instituições decisórias capazes de, em princípio, incorporarem as organizações da sociedade civil ao circuito das decisões políticas e possibilitarem o controle social das ações do Estado, permitiria maior transparência no uso dos recursos públicos e permeabilidade do Estado às demandas das parcelas mais subalternizadas da população, contribuindo para alterar o caráter autoritário, patrimonialista e clientelista que caracteriza as relações entre Estado e sociedade civil no Brasil.

Entretanto, inúmeros estudos das experiências de participação popular, realizados nas mais diferentes áreas do conhecimento no Brasil e no exterior, demonstraram algumas das fragilidades e insuficiências destes mecanismos (especificamente dos conselhos gestores das políticas) para efetivamente ampliar o debate em torno das políticas públicas, ampliar a participação de organizações da sociedade civil nos processos decisórios e alterar a correlação de forças entre capital e trabalho na definição das prioridades do Estado e distribuição dos recursos do fundo público via políticas sociais. Esses estudos apresentaram um quadro em que os conselhos gestores de políticas públicas têm pouca 
influência sobre a definição de prioridades, o financiamento e 0 desenho final das políticas. Transformaram-se, paralelamente, em espaços nos quais os gestores têm acesso facilitado a militantes e lideranças de movimentos sociais e também ampliam a audiência para os relatos de suas realizações, reduzindo o espaço para as críticas e confrontos.

Nesse sentido, o aumento das críticas ao funcionamento das instituições democráticas liberais e as demandas por participação direta, observado nas massivas manifestações de rua no mundo inteiro e no Brasil desde 2008, talvez pudessem afetar o funcionamento dos conselhos municipais de saúde, na medida em que estas instituições, ao mesmo tempo que fazem parte das estruturas decisórias do Estado e são, portanto, instituições do Estado, incorporam as organizações da sociedade civil no processo de decisão. Uma vez que a sociedade civil encontra-se em processo de mudanças, apresentando algumas inovações quanto às modalidades tradicionais de organização e mobilização dos cidadãos e que os conselhos apresentam inúmeras dificuldades em efetivamente ampliar a participação da sociedade civil nas decisões, essas mudanças, talvez, pudessem influenciar 0 atual padrão de funcionamento dos conselhos, de forma que uma ampliação dos participantes dos debates ou mesmo do processo decisório passassem a ser uma prioridade.

Os resultados da pesquisa que apresentamos neste artigo, indicam, todavia, que uma mudança nesse padrão de funcionamento ainda não está em curso.

Além da persistência de um padrão de funcionamento dos conselhos municipais de saúde muito similar ao do parlamento, a conjuntura pós-impeachment de Dilma Rousseff (PT), em 2016, fez avançar um projeto de poder no qual mesmo as regras do modelo liberal e elitista de democracia são desrespeitadas e a participação popular é considerada absolutamente desnecessária. ${ }^{11}$ No atual cenário, observamos o empenho do governo federal em desmanchar todas as instâncias expressivas do chamado projeto democrático-participativo, extinguindo, reduzindo ou reconfigurando conselhos e dificultando a realização das conferências nacionais de políticas públicas. Mesmo que o funcionamento dessas instâncias apresente muitas limitações em sua capacidade de efetivamente influir sobre políticas e programas públicos, o objetivo parece ser o de destruir qualquer vestígio de um projeto político que, mesmo de forma muito limitada, pautou a necessidade de uma gestão do Estado em que os interesses de trabalhadores e população subalternizada pudessem ganhar alguma visibilidade na disputa em torno do uso dos recursos públicos.

Observamos em toda a pesquisa a permanência de alguns padrões no processamento das decisões e no tipo de participação popular proporcionado pelo funcionamento dos conselhos municipais de saúde estudados. Padrões observados em pesquisas anteriores e indicativos de que mudanças nas instituições democráticas construídas após 1988 ainda não se processaram, fragilizando 
ainda mais sua capacidade de democratizar o Estado em uma conjuntura de avanço do autoritarismo social e governamental.

Nesse contexto, entre as tendências contemporâneas da participação popular observadas nesta investigação destacamos:

a) O predomínio do executivo nos processos decisórios. Em geral, os representantes do executivo municipal definem a pauta das reuniões, mesmo com a existência das mesas diretoras, dirigem os encontros e são capazes de fazer prevalecer suas propostas, valendo-se, frequentemente, da ausência de discussão prévia dos temas da pauta pelos demais conselheiros, do domínio das informações, inclusive legais, que dizem respeito aos temas, da ausência dos representantes de usuários e trabalhadores e da exiguidade dos prazos para a tomada de algumas decisões.

b) Esvaziamento do papel dos conselhos no circuito decisório. As questões substantivas da política (prioridades, orçamento, funcionamento) não são discutidas nos conselhos. Os conselheiros são informados. Os planos municipais de saúde são elaborados por técnicos das secretarias municipais de saúde, frequentemente sem a participação dos conselheiros. Pronto o plano, as discussões do mesmo seguem um rito rápido, quase sempre apenas formal.

c) Os conselhos têm pouca ou nenhuma relação com organizações da sociedade civil. Os conselhos estudados não possuem formas de comunicação e articulação com as organizações da sociedade civil que não estão representadas nos conselhos, dificultando a apreensão de demandas que não estão no escopo das organizações com assento nos conselhos.

d) Relação de descolamento entre conselheiros e sociedade e entre os conselheiros, as organizações que representam e as demais organizações da sociedade civil. Os conselhos não possuem mecanismos de comunicação com a sociedade que possibilitem tanto divulgar os debates e ações dos conselhos, quanto apreender melhor as demandas dos usuários e de organizações da sociedade civil. Os conselheiros também não desenvolveram iniciativas nessa direção. As novas tecnologias de informação e comunicação ainda não são largamente utilizadas para o debate dos temas em pauta nos conselhos ou para mobilizar a população a debater tais temas.

e) Ausência não apenas de canais efetivos de comunicação entre conselhos e sociedade, mas de atividades que possibilitem a participação popular na 
discussão dos temas que dizem respeito à política de saúde como assembleias ou plenárias populares ou a criação de grupos de trabalho com organizações não representadas nos conselhos.

Estas tendências indicam que, no momento, a participação popular na gestão da política de saúde proporcionada pelos conselhos ainda é restrita. Os conselhos funcionam como um mecanismo de passagem, fazem parte do conjunto de instituições requeridas para a tomada de decisões no interior da política de saúde, mas não constituem uma instância capaz de criar travas no processo decisório que obriguem ou induzam os gestores a ampliar efetivamente o debate em torno da política de saúde. Sua capacidade de ampliar o diálogo com o conjunto da sociedade civil tem sido débil, uma debilidade reforçada pelas dificuldades apresentadas por movimentos sociais para tensionar e pressionar as instâncias participativas.

\section{REFERÊNCIAS}

ALMEIDA, Carla; TATAGIBA, Luciana. Os conselhos gestores sob o crivo da política: balanços e perspectivas. Serviço Social e Sociedade, São Paulo, n.109, p.68-92, jan/mar.2012.

AVRITZER, Leonardo. O orçamento participativo e a teoria democrática: um balanço crítico. In: AVRITZER, Leonardo e NAVARRO, Zander (org.). A inovação democrática no Brasil. São Paulo: Cortez, 2003. 2009, (Democracia participativa).

(org.). Experiências nacionais de participação social. São Paulo: Cortez,

BEZERRA, Carla Paiva. Instituições participativas geram efeitos redistributivos? desafios metodológicos para a análise. Trabalho apresentado no III Encontro Nacional de Participação e Políticas Públicas, UFES, 30 de maio à 06 de junho de 2017.

BRAVO, Maria Inês Souza; MENEZES, Juliana Souza Bravo de. (orgs.). Saúde, Serviço Social, movimentos sociais e conselhos: desafios atuais. São Paulo: Cortez, 2012.

CORREIA, Maria Valéria Costa. Desafios do controle social na atualidade. Serviço Social e Sociedade, São Paulo, n.109, p.126-150, jan/mar.2012.

DAGNINO, Evelina (org.). Sociedade civil, espaços públicos e a construção democrática no Brasil: limites e possibilidades. In DAGNINO, Evelina (org.). Sociedade Civil e espaços públicos no Brasil. São Paulo: Paz e Terra, 2002.

FERRAZ, Ana Targina Rodrigues. Impactos da experiência conselhista sobre as atividades políticas e organizativas dos movimentos sociais na saúde: o caso do movimento popular de saúde de Campinas/São Paulo. 2005, 175 f. Tese (Doutorado em Ciências Sociais) - Programa de Pós-Graduação em Ciências Sociais, Universidade Estadual de Campinas, Campinas, 2005. 
.Cenários da participação política no Brasil: os conselhos gestores de políticas públicas. Serviço Social e Sociedade, São Paulo, v.88, p.59-74, 2006.

JUNIOR, Orlando Alves dos Santos; RIBEIRO, Luiz César de Queiroz; AZEVEDO, Sérgio. Governança democrática e poder local: a experiência dos conselhos municipais no Brasil. Rio de Janeiro: Revan, FASE, 2004.

SANTOS, Boaventura de Sousa, (org.). Democratizar a democracia: os caminhos da democracia participativa. Rio de Janeiro: Civilização Brasileira, Introdução geral à coleção, p. 13-28, Introdução v.1, p. 39-82, 2002.

SHUMPETER, Joseph A. Capitalismo, Socialismo e Democracia. Rio de Janeiro: Zahar editores, Parte IV, cap. XXII, p. 336-353, 1984.

TATAGIBA, Luciana Ferreira. Os conselhos e a construção da democracia no Brasil: um rápido balanço de duas décadas de participação conselhista. In: RUBIM, Antonio Albino Canelas, FERNANDES, Taiane, RUBIM, luri. (orgs.). Políticas culturais, democracia e conselhos de cultura. Salvador: EDUFBA, 2010, p.27-49.

WAMPLER, Brian. Contentiuos politics and participatory democracy in Brazil. Política \& Sociedade, Florianópolis, v. 13, n.28, set./dez. de 2014, p. 199-224.

\section{Notas}

1 Entre os muitos estudos realizados neste período podemos citar ALMEIDA, Carla; TATAGIBA, Luciana, 2012; BRAVO, Maria Inês Souza; MENEZES, Juliana Souza Bravo de, 2012; Bravo, Maria Inês Souza, CORREIA, Maria Valéria Costa, 2012, AVRITZER, Leonardo, 2009; DAGNINO, Evelina, OLVERA, Alberto J, PANFICHI, Aldo, 2006; FERRAZ, Ana Targina Rodrigues, 2006; JUNIOR, Orlando Alves dos Santos; RIBEIRO, Luiz César de Queiroz; AZEVEDO, Sérgio, 2004; AVRITZER, Leonardo, NAVARRO, Zander, 2003; DAGNINO, Evelina, 2002; SANTOS, Boaventura de Souza, 2002.

2 Em trabalho de 2009, Leonardo Avritzer listou a realização de 36 conferências nacionais durante a primeira gestão de Lula da Silva (2003-2006). Dentre essas, 15 conferências foram realizadas pela primeira vez e 07 pela segunda vez. (AVRITZER, 2009).

3 Dados coletados a partir das informações disponíveis no SIACS (Sistema de Acompanhamento dos Conselhos de Saúde) na página do Conselho Nacional de Saúde, da documentação disponível (em particular as atas) nas páginas das prefeituras, das observações de suas reuniões e do monitoramento das suas formas de comunicação. O objetivo foi verificar como os conselhos tem se relacionado com as mais recentes experiências de organização dos movimentos sociais (coletivos, redes e fóruns) e compreender se essas experiências tiveram algum impacto, no sentido de produzir mudanças, sobre as formas de organização e comunicação dos conselhos municipais de saúde.

${ }^{4}$ Em Vitória, para participar do conselho, o núcleo da RNP+ se formalizou como Associação de Pessoas Vivendo com HIVI/AIDS do Estado do Espírito Santo (APVHA).

5 Foram observadas 04 reuniões do conselho municipal de saúde de Cariacica, 05 reuniões do conselho municipal de saúde da Serra, 02 reuniões do conselho municipal de saúde de Vila Velha e 03 reuniões do conselho municipal de saúde de Vitória.

6 Tive acesso ao plano e muitas das metas apresentadas pelo mesmo não eram devidamente justificadas com base nas necessidades de saúde do município, mas apenas no incremento dos percentuais de atendimento em relação aos atendimentos realizados no ano anterior. 
${ }^{7}$ Apresentação de uma proposta de pauta, aceitação ou não pela mesa diretora do conselho da proposta, inclusão na pauta, discussão em reunião do conselho, solicitação de uma resposta ao gestor da política.

${ }^{8} \mathrm{~A}$ entrega das gestões das unidades de saúde e dos hospitais do SUS para as organizações sociais, a terceirização dos trabalhadores e de serviços, a criação da EBSERH e a criação das fundações estatais de direito privado para gestão dos equipamentos públicos.

${ }^{9} \mathrm{~A}$ universalidade, a equidade, a qualidade, o caráter prioritariamente público e a gestão direta do Estado.

${ }^{10}$ Apesar deste potencial crítico e de mobilização, estas novas modalidades de movimentos sociais também tem enfrentado dificuldades organizativas, de articulação e mobilização.

11 Os decretos 9.759/2019 e 10.003/2019 da presidência da república extinguiram inúmeros conselhos de políticas e programas públicos, bem como reconfiguraram ou desfiguraram (caso do Conselho Nacional dos Direitos da Criança e do Adolescente) outros de modo a reduzir a participação de organizações da sociedade civil nestas instâncias, sinalizando que a participação, o compartilhamento de poder decisório e o controle social sobre as ações do Estado não tem qualquer lugar neste projeto. 